\title{
Viability of Spray Dried Probiotics in Crumble Feed during Storage
}

\author{
N. Muthusany, A. Natarajan*, G. Kumerasan, A. Raja, N. Karthikeyan, \\ M.R. Purushothaman and P. Vasanthakumar \\ Department of Animal Nutrition, Veterinary College and Research Institute, \\ TANUVAS, Namakkal - 637 002, India \\ *Corresponding author
}

Keywords

Probiotics, Skim milk powder, Spray drying, Crumble feed, Viability

Article Info

Accepted:

14 June 2020

Available Online:

10 July 2020

A B S T R A C T

A study was conducted to assess the viability of spray dried probiotics in crumble feed during storage. The Bacillus subtilis (T1), Bacillus amyloliquefaciens (T2), Bacillus coagulans (T3), Bacillus clausii (T4), Lactobacillus acidophilus (T5) and Bifidobacterium bifidum (T6) cultures were propagated using skim milk and spray dried by using spray drier. The spray dried probiotic powder was diluted with water and sprayed on broiler crumble feed. After spraying, crumble feed was stored in room temperature $\left(25-33^{\circ} \mathrm{C}\right)$ for 0,7 and 14 days and the viability of probiotics was assessed before and after spray drying and during storage with crumble feed. $B$. clausii showed better yield after spray drying while B. subtilis showed highest survival rate $(83 \%)$ among all probiotics studied. At the end of 14 days of storage, the survival rate was maximum in B. amyloliquefaciens among spore forming probiotics $(95.61 \%)$ and among non-spore forming probiotics the $B$. bifidum (85.24\%) evinced better survival.

\section{Introduction}

Probiotics are viable microorganisms which when administered in adequate amounts confer a health benefit for all animals and human beings (WHO, 2001). As early as 1910, probiotics were known for their probiotic character in overcoming many gut related problems. When antibiotics came to limelight for countering many pathogens, the use of probiotics dropped during middle of the $20^{\text {th }}$ century. However, the revival of use of probiotics was seen in late $70 \mathrm{~s}$ in different forms and combinations for larger animals, pigs and poultry. The beneficial and advantage of probiotics are increasingly felt useful when use of antibiotics is gradually opposed for reasons like development of antimicrobial resistance through food producing animals. Further, the role of antibiotics in food producing animals started to diminish when the system of growing 
animals and birds was optimal and increasingly banned in many countries. The European Union, in 1999, banned the use of certain major antibiotics as growth promoters to prevent spread of antimicrobial resistance to humans (Casewell et al., 2003).

Probiotic is one of the commonly used and effective alternatives to AGPs and its use is documented since ages. Lactobacillus and Bifidobacterium are the earliest probiotics used traditionally in various fermented foods (Shortt, 1999). With the feed industry fast changing from mash type to pellet/crumbles, the use of Lactobacillus and Bifidobacterium in pellet/crumble type of feeds is to be discontinued as both are thermo-sensitive and get destroyed during pelletizing temperature. Alternately, thermo resistant spore forming probiotics, mostly bacillus type of organisms dominated. As reported by Tam et al.,(2006) that the bacillus are categorized as part of the gut microflora and by Cartman et al.,(2008) that the orally administered spores of Bacillus subtilis germinated in the gastrointestinal tracts of chicken, bacillus type organisms were increasingly accepted as alternates to the thermolabile characterized probiotics. In addition, bacillus species has long shelf life and retain its viability during storage and distribution of feeds.

These properties are highly desirable from a commercial perspective and spores based Bacillus species were used as direct-fed microbial (DFM) feed supplements. It is identified that about 13 Bacillus species with QPS status, including $B$. subtilis, $B$. amyloliquefaciens, $B$. licheniformis, $B$. Coagulans and B. Megaterium are used as probiotic candidates in animal feeds (EFSA BIOHAZ Panel, 2013) and these Bacillus species were identified as safe mainly due to absence of enterotoxins and emetic toxins. However, FAO (2016) cautioned that the use of Bacillus type of probiotics is not risk free, as some bacillus species are pathogenic to human (Schoeni and Lee Wong, 2005) and went on to comment that Lactobacillus and Bifidobacterium are probably the safest microorganisms because they are traditionally used in fermented foods (Shortt, 1999). The use of Lactobacillus and Bifidobacterium, naturally present in age-old conventional and traditional foods, was to be continued in the feed for food animals. It needs data with respect to the longevity of these two thermolabile probiotic candidates when spraydried and used in pellet/crumble feed for certain duration of storage. These data are currently not available to plan further on the use of them in pellets/crumbles. Hence, an invitro experiment was designed to find the effect of storage of crumble feeds mixed with spray dried Lactobacillus and Bifidobacterium microorganisms, which might help to take-up further experimental invivo trials on the use of Lactobacillus and Bifidofbacterium in feeding the food animals. The newer and recent bacillus types of probiotic candidates are also included in the study for knowledge of getting data by comparison.

\section{Materials and Methods}

Bacillus subtilis (NDRI strain), Bacillus amyloliquefaciens (ATCC 23842), Bacillus coagulans (ATCC 7050), Bacillus clausii (BCL 2B), Lactobacillus acidophilus (Russian strain) and Bifidobacterium bifidum (HI 48) were selected as probiotics candidates for this study and obtained from National Dairy Research Institute, NDRI, Karnal, Mystical Biotech Private Limited, Hoskote562114, Karnataka and Anthem Biosciences Pvt, Ltd, Harohalli Industrial Area, Phase-II, Kanakapura Taluk, Ramanagara District-562 112, Karnataka.

Bacillus organisms were propagated in nutrient broth and incubated at $39^{\circ} \mathrm{C}$ for 12 
hours (Shearer et al., 2000). Lactobacillus acidophilus was propagated in MRS broth, while Bifidobacterium bifidum was propagated in modified MRS (supplemented with L-cysteine hydrochloride, $0.5 \mathrm{~g} / \mathrm{L}$ ) broth as per the protocol described (Miranda et al.,2014).

Five hundred microlitres of propagated culture of Bacillus subtilis, Bacillus amyloliquefaciens, Bacillus coagulans, Bacillus clausii, Lactobacillus acidophilus and Bifidobacterium bifidum were added in sterile $1.5 \mathrm{~mL}$ tubes containing 500 microlitres of $20 \%$ glycerol (v/v) (Pop et al., 2015). The $1.5 \mathrm{~mL}$ tubes were stored at $-20^{\circ} \mathrm{C}$ for further propagation.

\section{Propagation of probiotic organisms}

Glycerol broth cultures of $B$. subtilis, B.amyloliquefaciens, B.coagulans, B.clausii, L. acidophilus and Bifidobacterium bifidum were propagated by using growth media and inoculated at the rate of 5 per cent into reconstituted skim milk (20\%) and incubated at $39^{\circ} \mathrm{C}$ for $10-12 \mathrm{hrs}$ for spray drying (Chavez and Ledeboer, 2007 and Ananta et al., 2005).

\section{Spray drying and recovery}

The cultures propagated in the skim milk medium were spray dried by using an automatic glass spray dryer (Milk-Tech Engineers, Bangalore, India) with a $0.7 \mathrm{~mm}$ single fluid nozzle. The solution was sprayed in a co-current flow with air as drying medium. The inlet air temperature used for spray drying of culture ranged from $180^{\circ} \mathrm{C}$ $185^{\circ} \mathrm{C}$ and outlet temperatures was adjusted to $90-95^{\circ} \mathrm{C}$ for all the cultures used in this study, after initial standardization of optimal outlet temperature for better yield and minimal loss of probiotics. Spray dried powder was collected as fine particles and transferred into pouches, sealed and stored at $4^{\circ} \mathrm{C}$. The yield (\%) was calculated as follows

Yield $(\%)=($ Total solid - recovered solids $) /$ Total solids X 100

Samples of spray dried probiotics were taken for microbiological examination before and immediately after spray drying and number of viable cells were enumerated (Chavez and Ledeboer, 2007).

\section{Spraying on crumble feed}

Three grams each of spray dried cultures of $B$. subtilis, B.amyloliquefaciens, B.coagulans, B.clausii, L.acidophilus and B.bifidum were separately mixed with $40 \mathrm{ml}$ of sterile distilled water and sprayed on $3 \mathrm{~kg}$ of sterile broiler crumble feed with 6 replicates each. After spraying, the feed were kept in a sealed HDPE polythene bag in room temperature (Maximum $33^{\circ} \mathrm{C}$ and Minimum $25^{\circ} \mathrm{C}$ ) for 0,7 and 14 days.

\section{Assessment of viability of probiotics}

The number of viable cells before and after spray drying and during storage $(0,7$ and 14 days) in crumble feed was enumerated by using spread plate technique. The probiotic samples and feed were dissolved in autoclaved saline water and serial dilution was prepared for each probiotic. All diluted samples of Bacillus spp., L. acidophilus and B. Bifidum were spread on nutrient agar, MRS agar and Modified MRS agar (added with $0.05 \%$ cysteine) plates respectively. The Nutrient agar plates were incubated at $37^{\circ} \mathrm{C}$ for $24 \mathrm{~h}$. The modified MRS agar plates and MRS agar plates were incubated anaerobically at $37^{\circ} \mathrm{C}$ for 24 hour.

After incubation, colonies were enumerated and mean number of bacteria was expressed as cfu/ml. Survival rates were calculated as 
follows: Survival $(\%)=\mathrm{N} / \mathrm{N}_{0} \times 100$, where $\mathrm{N}_{0}$ and $\mathrm{N}$ represent the number of bacteria before and after spray drying, respectively.

\section{Results and Discussion}

\section{Yield of probiotics after spray drying}

An attempt was made to spray dry the probiotics propagated in nutrient broth. It was found that the nutrient broth got stuck to the walls of drying chamber and impacted the collection of dried powder. The probiotics were spray dried after propagation in reconstituted skim milk $(20 \%)$ as per the procedure adopted by Ananta et al., (2005) who reported that the skim milk powder based medium provided high yield with better protection for lactobacilli

The yield of the spray dried products is presented in Table 1. The highest yield was observed in Bacillus clausii (38\%) and lowest was seen in B. bifidum (29\%).While in this study yield of $B$. coagulans was (33\%). Panday and Vakil (2017) found that the biomass of skim milk based $B$. coagulans was $46 \%$. The bacillus organisms had generally higher yield (31-38\%). However, non spore formers had lowest yield of 29-30\%, probably due to their thermolabile characters. Ananta et al., (2005) reasoned that the carrier used in spray drying encapsulated the probiotics and accounted for $10-50 \%$ of weight of entire spray dried powder.

\section{Assessment of viability of probiotics}

Viability of spore forming (B. subtilis, $B$. amyloliquefaciens, $B$. coagulans and $B$. clausii) and non-spore forming ( $L$. acidophilus and $B$. bifidum) probiotics was assessed before and after spray drying and during storage of crumble feed and the data are presented in Table 2 and are also figuratively expressed in Figure1.

\section{Loss of viability probiotics before and after spray drying}

The initial concentration of Bacillus subtilis before spray drying the reconstituted skimmed milk was $12.79 \log \mathrm{cfu} / \mathrm{ml}$, which after spray drying was found to be decreased by $17 \%$ to $10.56 \log \mathrm{cfu} / \mathrm{ml}$.

The initial count of Bacillus amyloliquefaciens before spray drying was $14.78 \log \mathrm{cfu} / \mathrm{ml}$, which decreased during spray drying by $3.10 \mathrm{log} \mathrm{cfu} / \mathrm{ml}$ (21\%) to $11.68 \mathrm{log} \mathrm{cfu} / \mathrm{ml}$. Bacillus amyloliquefaciens spores suspended in mashed carrot was reported to have a viable count of 8 $\log _{10} \mathrm{cfu} / \mathrm{ml}$ and after spray drying the count was decreased by $3.1 \mathrm{log} \mathrm{cfu} / \mathrm{ml} \quad(39 \%)$ (Castellvi et al., 2010) in an earlier work.

Bacillus coagulans population before spray drying was $11.33 \log \mathrm{cfu} / \mathrm{ml}$ and it drastically decreased during spray drying process to 8.55 $\log \mathrm{cfu} / \mathrm{ml} 2.78 \log \mathrm{cfu} / \mathrm{ml}$ which was $21 \%$. In a recent work, a viability loss of Bacillus coagulans was observed in the range of 2040\% (Pandey and Vakil, 2017).

Bacillus clausii concentration before spray drying was $15.75 \log \mathrm{cfu} / \mathrm{ml}$ which after spray drying lost by $3.21 \log \mathrm{cfu} / \mathrm{ml}(20 \%)$ to have a final concentration of $12.54 \log \mathrm{cfu} / \mathrm{ml}$.

The initial population of Lactobacillus acidophilus was $15.24 \log \mathrm{cfu} / \mathrm{ml}$ before spray drying and there was a huge decline by a margin of more than one third (36\%) to 9.73 $\log \mathrm{cfu} / \mathrm{ml}$ after spray drying. A similar viability loss of about $35 \%$ was also reported in Lactobacillus rhamnosus after spray drying (Anata et al., 2005) where in however the initial count of Lactobacillus acidophilus was only $5.28 \log \mathrm{cfu} / \mathrm{ml}$ before spray drying.

While B. bifidum had a concentration of 10.29 $\log \mathrm{cfu} / \mathrm{ml}$ before spray drying, the decrease 
in its microbial population was by $2.14 \mathrm{log}$ $\mathrm{cfu} / \mathrm{ml}(21 \%)$ to a final value of $8.05 \mathrm{log}$ $\mathrm{cfu} / \mathrm{ml}$ after spray drying. In contrast, the viability loss of spray dried $B$. bifidum was reported to be $70 \%$ and reduction in viability was due to use of maltodextrin as a carrier during spray drying (Shokriet al., 2015) in earlier works.
Non-spore formers are thermolabile and prone to get destroyed at spray drying temperature. As per the water replacement theory (Crowe et al., 1998), skim milk contains lactose, which replaces the water in the cell membrane that results in direct interaction with the phospholipids of cellular membrane and there by protects the probiotics during spray drying and prolonged storage.

Table.1 Yield of probiotics after spray drying

\begin{tabular}{|l|c|c|}
\hline \multicolumn{1}{|c|}{ Treatment } & Yield of spray dried powder (g) & $\begin{array}{c}\text { Recovery } \\
\text { (\%) }\end{array}$ \\
\hline Bacillus subtilis (T1) & 72 & 36 \\
\hline Bacillus amyloliquefaciens (T2) & 61 & 31 \\
\hline Bacillus coagulans(T3) & 65 & 33 \\
\hline Bacillus clausii (T4) & 76 & 38 \\
\hline Lactobacillus acidophilus (T5) & 61 & 30 \\
\hline Bifidobacteriumbifidum (T6) & 58 & 29 \\
\hline
\end{tabular}

Table.2 Viability of probiotics before and after spray drying and during storage on broiler crumble feed

\begin{tabular}{|c|c|c|c|c|c|c|}
\hline \multirow[t]{3}{*}{ Treatment } & \multicolumn{6}{|c|}{ Loss of viability $\left(\log _{10} \mathrm{cfu} / \mathrm{ml}\right)$} \\
\hline & \multicolumn{3}{|c|}{ Spray drying } & \multicolumn{3}{|c|}{ Crumble feed with probiotics } \\
\hline & Before & After & $\begin{array}{c}\text { Loss in } \\
\text { viability in } \\
\text { absolute values } \\
\text { and (\%) }\end{array}$ & $\begin{array}{c}\text { Viability } \\
\text { immediately } \\
\text { after mixing with } \\
\text { feed ( } 0 \text { day) }\end{array}$ & $\begin{array}{l}\text { After } 7 \text { days } \\
\text { of storage } \\
\text { (Loss in \%) }\end{array}$ & $\begin{array}{l}\text { After } 14 \\
\text { days of } \\
\text { storage } \\
(\text { Loss in \%) }\end{array}$ \\
\hline Bacillus subtilis(T1) & 12.79 & 10.56 & $\begin{array}{l}2.23 \\
(17)\end{array}$ & 7.51 & $\begin{array}{c}6.83 \\
(9.05)\end{array}$ & $\begin{array}{c}4.49 \\
(40.21)\end{array}$ \\
\hline $\begin{array}{l}\text { Bacillus } \\
\text { amyloliquefaciens(T2) }\end{array}$ & 14.78 & 11.68 & $\begin{array}{l}3.10 \\
(21)\end{array}$ & 8.88 & $\begin{array}{c}8.65 \\
(2.59)\end{array}$ & $\begin{array}{c}8.49 \\
(4.39)\end{array}$ \\
\hline Bacillus coagulans $(\mathbf{T 3})$ & 11.33 & 8.55 & $\begin{array}{l}2.78 \\
(21)\end{array}$ & 5.09 & $\begin{array}{c}2.87 \\
(43.61)\end{array}$ & $\begin{array}{c}2.75 \\
(45.97)\end{array}$ \\
\hline Bacillus clausii (T4) & 15.75 & 12.54 & $\begin{array}{l}3.21 \\
(20)\end{array}$ & 9.86 & $\begin{array}{c}9.45 \\
(4.16)\end{array}$ & $\begin{array}{c}7.80 \\
(20.89)\end{array}$ \\
\hline $\begin{array}{l}\text { Lactobacillus } \\
\text { acidophilus (T5) }\end{array}$ & 15.24 & 9.73 & $\begin{array}{l}5.51 \\
(36)\end{array}$ & 6.20 & $\begin{array}{c}4.47 \\
(27.90)\end{array}$ & $\begin{array}{c}4.28 \\
(30.97)\end{array}$ \\
\hline $\begin{array}{l}\text { Bifidobacterium } \\
\text { bifidum(T6) }\end{array}$ & 10.29 & 8.05 & $\begin{array}{l}2.14 \\
(21)\end{array}$ & 6.03 & $\begin{array}{c}5.50 \\
(8.79)\end{array}$ & $\begin{array}{c}5.14 \\
(14.76)\end{array}$ \\
\hline
\end{tabular}

Values in the parenthesis indicate that percentage of survival of probiotics. 
Fig.1 Survival of probiotics before and after spray drying and its spray on broiler crumble feed for 0,7 and 15 days of storage

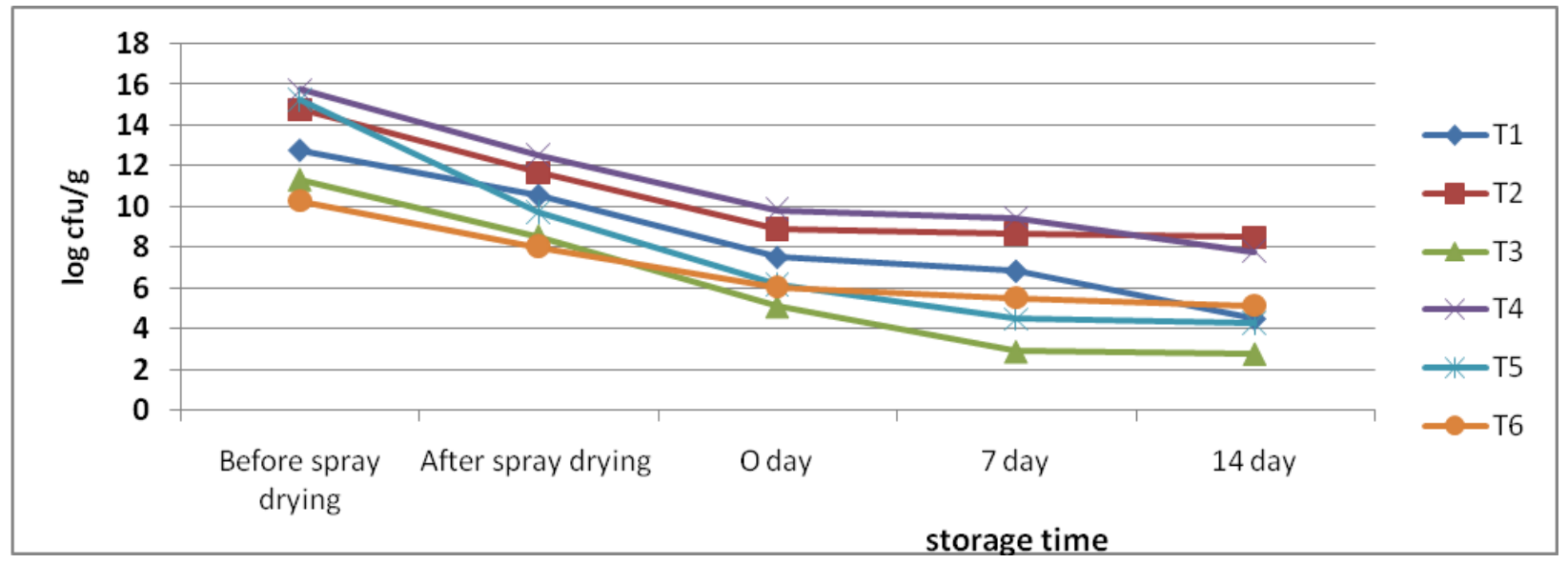

In this study, the viability of probiotics was found to decrease after spray drying. The loss of viability of probiotics may be attributed to damage of cytoplasmic membrane, the cell wall, ribosome and DNA at higher spray drying temperature (Gardiner et al., 2000; Meng et al., 2008).

The viability loss was found to be highest in L. acidophilus (36\%) and lowest in B. subtilis $(17 \%)$ after spray drying. Generally, nonspore forming probiotics are thermolabile and sensitive to high temperatures. However, the viability of L. acidophilus NCIMB 701748 post-spray drying was $7.37 \mathrm{log} \mathrm{cfu} / \mathrm{ml}$ after cruising an inlet temperature of $160^{\circ} \mathrm{C}$ and outlet temperature of $91.5^{\circ} \mathrm{C}$, with $30 \%$ loss of viability. The stationary phase bacterial cultures are more resistant to heat compared to bacterial cells in $\log$ growth phase (Jobbehdar et al., 2013). Bacteria that enter into stationary phase develop a general stress resistance than bacteria in the log-phase due to exhaustion nutrients that induce stress factors to allow survival of probiotics (Morgan et al., 2006; Vande Guchte et al., 2002).

Viability loss of spray dried probiotics on crumble feed during storage

As seen in the Table 2, the viability of
Bacillus subtilis decreased during 14 days of storage from $7.51 \log _{10} \mathrm{cfu} / \mathrm{ml}$ (0 day) to 4.49 $\log _{10} \mathrm{cfu} / \mathrm{ml}$ (day 14) in sterile broiler crumble feed stored at room temperature. While the loss of viability was only $9.05 \%$ during the first 7 day storage, the loss was higher during the second week storage $(31.16 \%)$.The loss increased quickly after 7 days of storage in crumble feed.

The loss of viability with respect to Bacillus amyloliquefaciens was very low. The decrease during the span of 14 days was only $4.39 \%$ (from $8.88 \log _{10} \mathrm{cfu} / \mathrm{ml}, 0$ day) to 8.49 $\left.\log _{10} \mathrm{cfu} / \mathrm{ml}\right)$. Bacillus amyloliquifaciens was found to withstand the storage time of 14 days without much loss as observed in B. subtilis.

While the viability loss of Bacillus coagulans in sterile broiler crumble feed due to storage of 14 days was found to be very higher (45.97 $\%$; from $5.09 \log _{10} \mathrm{cfu} / \mathrm{ml}$ to $2.75 \log _{10} \mathrm{cfu} / \mathrm{ml}$ ), it can be observed that the loss at the 7 day storage was $43.61 \%$. The loss in viability started as early as from 7 days of storage in the case of B. coagulans.

The viability of spore forming B.clausii in sterile broiler crumble feed was found to be in decreasing trend during the span of 14 days of storage from $9.86 \log _{10} \mathrm{cfu} / \mathrm{ml}$ (0 day) 7.80 $\log _{10} \mathrm{cfu} / \mathrm{ml}$ which was $20.89 \%$ loss. Not like 
$B$ coagulans, the viability loss was lower in the first 7 days $(4.16 \%)$ but there after it increased sharply between 7 and 14 days storage.

The viability of non-spore forming $L$. acidophilus in sterile broiler crumble feed decreased during storage the first 7 days was fairly faster by $27.90 \%$ (from 6.20 $\log _{10} \mathrm{cfu} / \mathrm{ml}$ on day 0 to $\left.4.47 \log _{10} \mathrm{cfu} / \mathrm{ml}\right)$ and thereafter the loss was minimal (from 4.47 $\log _{10} \mathrm{cfu} / \mathrm{ml}$ on day 7 to $4.28 \log _{10} \mathrm{cfu} / \mathrm{ml}$ on day 14 . In a similar work, the viability loss of lactic acid producing bacteria was reported to be higher (1.01 to $1.51 \log \mathrm{cfu} / \mathrm{ml})$ in first week than second week $(<0.5 \log \mathrm{cfu} / \mathrm{ml})$ of storage period (Olnood et al., 2015).

The count of non-spore forming B. bifidum in sterile broiler crumble feed decreased during the span of 14 days of storage from 6.03 $\log _{10} \mathrm{cfu} / \mathrm{ml}$ (0 day) to $5.50 \log _{10} \mathrm{cfu} / \mathrm{ml}$ (7 day) and to a final value of $5.14 \log _{10} \mathrm{cfu} / \mathrm{g}$ (14 day) which was equivalent to $14.76 \%$, while the \% loss on day 7 was 8.79 . The loss was progressively gradual on day 7 and 14 in case of B. bifidum.

The viability of probiotics was influenced by the storage environment, length of storage of the feed (Pollmann and Bandyk, 1984).

In conclusion, this study demonstrated that the reconstituted skim milk can be used as medium for spray drying of probiotics. The survival rate of spore forming and non-spore forming probiotics was above $60 \%$ after spray drying. In this study, Bacillus clausii gave better yield after spray drying. Survival rate of Bacillus subtils was highest after spray drying amongst the probiotics studied. Bacillus amyloliquefaciens among the spore forming bacteria and B. bifidum among the non-spore forming bacteria survived better in the crumble feed during storage of 14 days. After 14 days of storage in feed, the overall viability loss was lowest in Bacillus amyloliquefaciens followed by Bifidobacterium bifidum, Bacillus clausii, Lactobacillus acidophilus, Bacillus subtilis and Bacillus coagulans.

\section{References}

Ananta, E., M.Volkert and Knorr, D. 2005. Cellular injuries and storage stability of spray-dried Lactobacillus rhamnosus GG. International Dairy Journal.15: 399-409.

Cartman, S.T., M. Roberto, M. L. Ragione and Woodward. M.J. 2008. Bacillus subtilis spores germinate in the chicken gastrointestinal tract. Applied and Environmental Microbiology. 74 (16): 5254-5258.

Casewell, M., CFriis, E.Marco, P.McMullin and Phillips I. 2009. The European ban on growth- promoting antibiotics and emerging consequences for human and animal health. Journal of Antimicrobial Chemotherapy. 52: 159-161.

Castellvi, D.S., W. Ratphitagsanti, V. M. Balasubramaniam and Yousef A.E. 2010. Inactivation of Bacillus amyloliquefaciensspores by a combination of sucrose laurate and pressure- assisted thermal processing. Journal of Food Protection, 73(11):2043-2052

Chavez, B.E., and Ledeboer, A.M. 2007. Drying of Probiotics: Optimization of Formulation and Process to Enhance Storage Survival.Drying Technology. 25: 1193-1201.

Crowe, J.H., J. F. Carpenter and Crowe, L.M. 1998. The role of vitrification in anhydrobiosis. Annual Review of Physiology. 60: 73-103.

Yadav, S.B., A. V. Klieve, P.J. Dart, W. L. Bryden and Editor Harinder P.S. Makkar P.S. FAO. 2016. Animal Production and Health Paper No. 179. Rome.

Gardiner, G.E., E. O. Sullivan, J. Kelly, M. A. E. Auty, G. F. Fitzgerald, J. K. Collins, R.P. Ross and Stanton C. 2000. Comparative survival rates of human-derived probiotics 
Lactobacillus paracasei and Lactobacillus salivarius strains during heat treatment and spray drying. Applied and Environmental Microbiology. 66(6):2605-12.

Jobbehdar, B.S., C. Soukoulis, L. Yonekura and Fisk I. 2013. Optimization of spray-drying process conditions for the production of maximally viable microencapsulated $L$. Acidophilus NCIMB 701748. Drying Technology.31(11):1274-1283.

Meng, X.C., C.Stanton, G. F. Fitzgerald, C. Daly and Ross R.P. 2008. Anhydrobiotics: The challenges of drying probiotic cultures. Food Chemistry. 106(4): 1406-1416.

Miranda, R.O., A.F. Carvalho and Nero. L.A.2014. Development of a selective culture medium for bifidobacteria, Raffinose - Propionate Lithium Mupirocin (RP-MUP) and assessment of its usage with Petrifilm Aerobic Count plates. Food Microbiology. 39:96-102.

Morgan, C.A., N. Herman, P. A. White and Vesey G.2006.Preservation of microorganisms by drying: A review. Journal of Microbiological Methods. 66: 183-193.

Olnood, C.G., S. S. M. Beski, M. Choct andIji, P.A. 2015. Novel probiotics: Their effects on growth performance, gut development, microbial community and activity of broiler chickens. Animal Nutrition. 1: 184-191

Pandey, K.R. and Vakil, B.V.2017. Encapsulation of probiotic Bacillus coagulans for enhanced shelf Life. Journal of Applied Biology \& Biotechnology. 5(04):057-065.

Pollmann, D.S., and Bandyk, C.A.1984. Stability of viable lactobacillus products. Animal Feed Science and Technology.11:
261-267.

Pop, O.L., Z. Diaconeasa, T. Brandau, O. Ciuzan, D. Pamfil, D.C. Vodnar and Socaciu, C. 2015. Effect of glycerol, as cryoprotectant in the encapsulation and freeze drying of microspheres containing probiotic cells. Food Science and Technology.72(1): 28-32

Schoeni, J.L., and Wong, L.A.C.2005. Bacillus cereus food poisoning and its toxins. Journal of Food Protection. 68(3): 636-648.

Shearer, A.E.H., C. P. Dunn,E, A. Sikes, and Hoover, D.G.2000. Bacterial spore inhibition and inactivation in foods by pressure, chemical preservatives, and mild heat.Journal of Food Protection, 63(11): 1503-1510.

Shokri, Z., M.R. Fazeli, M. Ardjmand, S. M. Mousavi and Gilani K. 2015. Factors affecting viability of Bifidobacterium bifidum during spray drying. DARU Journal of Pharmaceutical Sciences. 23(7): 1-9.

Shortt,C.1999. The probiotic century: historical and current perspectives. Trends in Food Science and Technology. 10(12): 411-417.

Tam,N.K.M., N. Q. Uyen, H. A. Hong, L. H. Duc, T.T. Hoa, C. R. Serra, A.O. Henriques and Simon M.C.2006. The intestinal life cycle of bacillus subtilis and close relatives. Journal of Bacteriology. 188 (7): 26922700 .

VandeGuchte, M., P.Serror, C.Chervaux, T. Smokvina, S. D. Ehrlich and Maguin E. 2002. Stress responses in lactic acid bacteria. Antonie Van Leeuwenhoek. 82: 187-216.

\section{How to cite this article:}

Muthusany, N., A. Natarajan, G. Kumerasan, A. Raja, N. Karthikeyan, M.R. Purushothaman and Vasanthakumar, P. 2020. Viability of Spray Dried Probiotics in Crumble Feed during Storage. Int.J.Curr.Microbiol.App.Sci. 9(07): 1389-1396.

doi: https://doi.org/10.20546/ijcmas.2020.907.160 